\title{
Frontiers Commentary: The HEART Mobile Phone Trial: The Partial Mediating Effects of Self-Efficacy on Physical Activity among Cardiac Patients
}

\author{
Dan J. Graham* \\ Department of Psychology, Colorado School of Public Health, Colorado State University, Fort Collins, CO, USA
}

Keywords: mHealth, mobile phone, smartphone, physical activity, self-efficacy

\section{A commentary on}

The HEART Mobile Phone Trial: The Partial Mediating Effects of Self-Efficacy on Physical Activity among Cardiac Patients

by Maddison R, Pfaeffli L, Stewart R, Kerr A, Jiang Y, Rawstorn J, et al. Front Public Health (2014) 2:56. doi: 10.3389/fpubh.2014.00056

\section{OPEN ACCESS}

Edited by:

Matthew Lee Smith,

The University of Georgia, USA

Reviewed by:

Giada Pietrabissa,

Ospedale San Giuseppe, Italy

Melanie M. Adams,

Keene State College, USA

Brad Wipfli,

Oregon Health \& Science University,

USA

Yasser Khazaal,

Geneva University Hospitals,

Switzerland

*Correspondence:

Dan J. Graham

dan.graham@colostate.edu

Received: 30 October 2015 Accepted: 28 March 2016

Published: 15 April 2016

Citation:

Graham DJ (2016) Frontiers Commentary: The HEART Mobile Phone Trial: The Partial Mediating Effects of Self-Efficacy on Physical Activity among Cardiac Patients.

Front. Public Health 4:66. doi: 10.3389/fpubh.2016.00066
Maddison and colleagues' HEART mobile phone trial (1) presents dual insights that will be useful and important to those promoting physical activity $(\mathrm{PA})$ and other health behaviors in the twenty-first century. First, interventions delivered by smartphone can increase PA among a clinically important population (individuals with heart disease). Second, increasing self-efficacy is an important mechanism for mobile health (mHealth) interventions to target.

As has been demonstrated previously, self-efficacy is among PAs most reliable correlates and even determinants $(2,3)$. This robust relationship between self-efficacy and PA exists for children and adolescents (4-6) as well as younger and older adults (7-9). Furthermore, much intervention research has shown that successfully increasing PA self-efficacy leads to increased PA in both healthy and obese populations (10-12). Self-efficacy's enhancement of PA has been demonstrated via interventions delivered in-person (13), by print-based materials (14), by telephone (15), by mass media (16), by postal mail $(14)$, and by combinations of these $(17,18)$. Email has also been used to deliver PA intervention content with some success (19), and with smartphones representing one of the most rapidly adopted technologies ever documented (20), there is reason to believe that email and other smartphone-mediated delivery will be at least as successful in years to come. Although the HEART trial reveals the importance of increasing self-efficacy in the context of promoting PA (1), the principle is likely more broadly applicable. This evidence that self-efficacy can be effectively increased in mHealth interventions should be encouraging to public health practitioners aiming to improve not only PA but also other health behaviors that have been positively impacted by self-efficacy change in other intervention contexts. Reducing smoking and drinking, increasing contraceptive use, and healthy eating all have long established (21) as well as consistently and recently reaffirmed ties to increased self-efficacy (22-25).

Maddison and coauthors indicate that future mHealth research promoting PA would benefit from incorporating objective activity assessment (1); this is an increasingly feasible goal, even with largescale interventions. Smartphone-mediated interventions can permit accelerometers already present in smartphones, and already capable of assessing PA (26), to be linked with intervention apps, so that content could be tailored based on users' activity. For example, if a phone's accelerometer has 
not recorded some designated level of movement over the past two daytime hours, the user could receive a text message suggesting a brief walk. Such an alerting feature is available in some commercial activity monitors (e.g., Garmin vivofit, Jawbone UP) and could comprise a useful element of mHealth PA interventions. Additionally, interventions could incorporate persuasive technologies (27) like those used in home energy meters that glow one color when energy use is low and a different color when energy use is high. Similarly, smartphone users can benefit from simple visible cues to modify their own energy expenditure (28). Smartphones are already being used to assess PA speed and location (29), and as technology continues to advance, current obstacles to data quality such as sensor disruptions due to competing power demands or the phone being worn/carried in different positions (30) will likely diminish.

Maddison and colleagues provide encouraging evidence of mHealth success even in the absence of substantial tailoring of intervention content (1). The ability to tailor content, a strategy previously shown to be successful in increasing self-efficacy and PA (31) is enhanced substantially in mHealth interventions. It is reasonable to assume that tailored intervention content delivered to smartphones would improve intervention outcomes as tailoring has done through print delivery channels (32). Indeed, meta-analytic results identify tailoring based on self-efficacy as a particularly promising strategy (32). Moving forward, mHealth interventions may be even more successful if they employ active assistance technology (33) that is not only tailored, but adaptive (i.e., interacting with the user in an ongoing way, not merely utilizing one-time, a priori tailoring).

Online and smartphone-based games are also very popular, being played by nearly half of all Internet users (34). Gaming represents another excellent electronic venue through which interventionists can promote health behavior change [e.g., Ref. $(35,36)]$. Some health-promotion video games have produced beneficial effects by increasing self-efficacy for important health behaviors [e.g., Ref. $(37,38)]$. As video game technology provides increasingly immersive experiences, interventions incorporating gaming may well be even more effective in increasing player self-efficacy and health behaviors (39). Virtual reality technology

\section{REFERENCES}

1. Maddison R, Pfaeffli L, Stewart R, Kerr A, Jiang Y, Rawstorn J, et al. The HEART mobile phone trial: the partial mediating effects of self-efficacy on physical activity among cardiac patients. Front Public Health (2014) 2:56. doi:10.3389/fpubh.2014.00056

2. Bauman AE, Reis RS, Sallis JF, Wells JC, Loos RJ, Martin BW, et al. Correlates of physical activity: why are some people physically active and others not? Lancet (2012) 380(9838):258-71. doi:10.1016/S0140-6736(12)60735-1

3. McAuley E, Blissmer B. Self-efficacy determinants and consequences of physical activity. Exerc Sport Sci Rev (2000) 28(2):85-8.

4. Biddle SJ, Whitehead SH, O'Donovan TM, Nevill ME. Correlates of participation in physical activity for adolescent girls: a systematic review of recent literature. J Phys Act Health (2005) 2(4):423-34.

5. Craggs C, Corder K, van Sluijs EM, Griffin SJ. Determinants of change in physical activity in children and adolescents: a systematic review. Am J Prev Med (2011) 40(6):645-58. doi:10.1016/j.amepre.2011.02.025 could further enhance self-efficacy (e.g., by seeing one's virtual self engaging in efficacious health-promotion acts) (40).

The greatest potential barrier to mHealth interventions, the inability to access individuals who lack necessary electronic devices, is rapidly reducing. With over $50 \%$ of the populations of nearly 20 countries owning smartphones as of 2013 (41), and projections that over half of the world's $4+$ billion mobile phone users will have smartphones by 2016 (42), many more individuals will soon be able to access smartphone-mediated interventions. In several countries (e.g., South Korea, Australia, Israel, United States, Spain), smartphone ownership currently exceeds $70 \%$ (41). In the US, $64 \%$ of all Americans, and $85 \%$ of young adults, currently own smartphones, and these rates are rapidly increasing (e.g., only $35 \%$ of US adults owned smartphones 4 years ago) (43). In addition, mHealth interventions may not necessarily exclude those most in need of targeted efforts. Public health practitioners previously hampered by the inability to access those living in rural areas, low-income areas, and minority communities (44) may actually find mHealth programs wellsuited to reaching racial and ethnic minority groups that have traditionally faced greater health inequities (45). For example, rates of smartphone ownership are higher among Hispanic and Black Americans than among White Americans (43).

The success of the HEART mobile phone trial provides promising strategies for researchers and public health practitioners to adopt and expand upon. Future mHealth interventions may benefit from incorporating location- and/or movement-based content delivery, message tailoring, persuasive and active assistance technologies, video games, and dissemination to a variety of groups including at-risk populations. Such strategies have great potential to enhance public health in an affordable and far-reaching manner.

\section{AUTHOR CONTRIBUTIONS}

The author confirms being the sole contributor of this work and approved it for publication.

6. Van der Horst K, Paw M, Twisk JW, Van Mechelen W. A brief review on correlates of physical activity and sedentariness in youth. Med Sci Sports Exerc (2007) 39(8):1241. doi:10.1249/mss.0b013e318059bf35

7. Plonczynski DJ. Physical activity determinants of older women: what influences activity? Medsurg Nurs (2003) 12(4):213-21.

8. Rhodes RE, Martin AD, Taunton JE, Rhodes EC, Donnelly M, Elliot J. Factors associated with exercise adherence among older adults. Sports Med (1999) 28(6):397-411. doi:10.2165/00007256-199928060-00003

9. Trost SG, Owen N, Bauman AE, Sallis JF, Brown W. Correlates of adults' participation in physical activity: review and update. Med Sci Sports Exerc (2002) 34(12):1996-2001. doi:10.1097/00005768-200212000-00020

10. Ashford S, Edmunds J, French DP. What is the best way to change self-efficacy to promote lifestyle and recreational physical activity? A systematic review with meta-analysis. Br J Health Psychol (2010) 15(2):265-88. doi:10.1348/13 5910709X461752

11. Olander EK, Fletcher H, Williams S, Atkinson L, Turner A, French DP. What are the most effective techniques in changing obese individuals' physical 
activity self-efficacy and behaviour: a systematic review and meta-analysis. Int J Behav Nutr Phys Act (2013) 10(29):1-15. doi:10.1186/1479-5868-10-29

12. Williams S, French D. What are the most effective intervention techniques for changing physical activity self-efficacy and physical activity behaviour - and are they the same? Health Educ Res (2011) 26(2):308-22. doi:10.1093/her/ cyr005

13. Darker C, French D, Eves F, Sniehotta F. An intervention to promote walking amongst the general population based on an 'extended' theory of planned behaviour: a waiting list randomised controlled trial. Psychol Health (2010) 25(1):71-88. doi:10.1080/08870440902893716

14. Marcus BH, Napolitano MA, King AC, Lewis BA, Whiteley JA, Albrecht A, et al. Telephone versus print delivery of an individualized motivationally tailored physical activity intervention: project STRIDE. Health Psychol (2007) 26(4):401. doi:10.1037/0278-6133.26.4.401

15. Eakin EG, Lawler SP, Vandelanotte C, Owen N. Telephone interventions for physical activity and dietary behavior change: a systematic review. Am J Prev Med (2007) 32(5):419-34. doi:10.1016/j.amepre.2007.01.004

16. Bauman AE, Bellew B, Owen N, Vita P. Impact of an Australian mass media campaign targeting physical activity in 1998. Am J Prev Med (2001) 21(1):41-7. doi:10.1016/S0749-3797(01)00313-0

17. Blanchard CM, Fortier M, Sweet S, O'Sullivan T, Hogg W, Reid RD, et al. Explaining physical activity levels from a self-efficacy perspective: the physical activity counseling trial. Ann Behav Med (2007) 34(3):323-8. doi:10.1007/ BF02874557

18. Calfas KJ, Sallis JF, Oldenburg B, Ffrench M. Mediators of change in physical activity following an intervention in primary care: PACE. Prev Med (1997) 26(3):297-304. doi:10.1006/pmed.1997.0141

19. Plotnikoff RC, McCargar LJ, Wilson PM, Loucaides CA. Efficacy of an E-mail intervention for the promotion of physical activity and nutrition behavior in the workplace context. Am J Health Promot (2005) 19(6):422-39. doi:10.4278/0890-1171-19.6.422

20. Stewart J. Reaching 70\% Penetration, Smart Phones Cement Place as Rapidly Adopted Technology. Digital Transactions. (2014). Available from: http:// www.digitaltransactions.net/news/story/Reaching-70_-Penetration_-SmartPhones-Cement-Place-As-Rapidly-Adopted-Technology

21. Strecher VJ, DeVellis BM, Becker MH, Rosenstock IM. The role of self-efficacy in achieving health behavior change. Health Educ Behav (1986) 13(1):73-92. doi:10.1177/109019818601300108

22. Baldwin AS, Rothman AJ, Hertel AW, Linde JA, Jeffery RW, Finch EA, et al. Specifying the determinants of the initiation and maintenance of behavior change: an examination of self-efficacy, satisfaction, and smoking cessation. Health Psychol (2006) 25(5):626. doi:10.1037/0278-6133.25.5.626

23. Hendriksen ES, Pettifor A, Lee S-J, Coates TJ, Rees HV. Predictors of condom use among young adults in South Africa: the reproductive health and HIV research unit national youth survey. Am J Public Health (2007) 97(7):1241. doi:10.2105/AJPH.2006.086009

24. Hyde J, Hankins M, Deale A, Marteau TM. Interventions to increase selfefficacy in the context of addiction behaviours a systematic literature review. J Health Psychol (2008) 13(5):607-23. doi:10.1177/1359105308090933

25. Oei TP, Burrow T. Alcohol expectancy and drinking refusal self-efficacy: a test of specificity theory. Addictive Behav (2000) 25(4):499-507. doi:10.1016/ S0306-4603(99)00044-1

26. Dunton GF, Dzubur E, Kawabata K, Yanez B, Bo B, Intille S. Development of a smartphone application to measure physical activity using sensor-assisted self-report. Front Public Health (2014) 2:12. doi:10.3389/fpubh.2014.00012

27. Spahn A. And lead us (not) into persuasion...? Persuasive technology and the ethics of communication. Sci Eng Ethics (2012) 18(4):633-50. doi:10.1007/ s11948-011-9278-y

28. Consolvo S, Klasnja P, McDonald DW, Avrahami D, Froehlich J, LeGrand L, et al., editors. Flowers or a robot army?: encouraging awareness \& activity with personal, mobile displays. Proceedings of the 10th International Conference on Ubiquitous Computing. Seoul: ACM (2008).

29. Reddy S, Mun M, Burke J, Estrin D, Hansen M, Srivastava M. Using mobile phones to determine transportation modes. ACM Trans Sens Netw (2010) 6(2):13. doi:10.1145/1689239.1689243
30. Ellis K, Godbole S, Marshall S, Lanckriet G, Staudenmayer J, Kerr J. Identifying active travel behaviors in challenging environments using GPS, accelerometers, and machine learning algorithms. Front Public Health (2014) 2:36. doi:10.3389/fpubh.2014.00036

31. Marcus BH, Bock BC, Pinto BM, Forsyth LAH, Roberts MB, Traficante RM. Efficacy of an individualized, motivationally-tailored physical activity intervention. Ann Behav Med (1998) 20(3):174-80. doi:10.1007/BF02884958

32. Noar SM, Benac CN, Harris MS. Does tailoring matter? Meta-analytic review of tailored print health behavior change interventions. Psychol Bull (2007) 133(4):673. doi:10.1037/0033-2909.133.4.673

33. Kennedy CM, Powell J, Payne TH, Ainsworth J, Boyd A, Buchan I. Active assistance technology for health-related behavior change: an interdisciplinary review. J Med Internet Res (2012) 14(3):e80. doi:10.2196/jmir.1893

34. Takahashi D. More Than 1.2 Billion People Are Playing Games. (2013). Available from: http://venturebeat.com/2013/11/25/more-than-1-2-billionpeople-are-playing-games/

35. Giner-Bartolomé C, Fagundo AB, Sánchez I, Jiménez-Murcia S, Santamaría JJ, Ladouceur $\mathrm{R}$, et al. Can an intervention based on a serious videogame prior to cognitive behavioral therapy be helpful in bulimia nervosa? A clinical case study. Front Psychol (2015) 6:982. doi:10.3389/fpsyg.2015.00982

36. Merry SN, Stasiak K, Shepherd M, Frampton C, Fleming T, Lucassen MF. The effectiveness of SPARX, a computerised self help intervention for adolescents seeking help for depression: randomised controlled non-inferiority trial. $B M J$ (2012) 344:e2598. doi:10.1136/bmj.e2598

37. Brown SJ, Lieberman DA, Gemeny B, Fan YC, Wilson D, Pasta D. Educational video game for juvenile diabetes: results of a controlled trial. Med Inform (Lond) (1997) 22(1):77-89. doi:10.3109/14639239709089835

38. Khazaal Y, Chatton A, Prezzemolo R, Zebouni F, Edel Y, Jacquet J, et al. Impact of a board-game approach on current smokers: a randomized controlled trial. Subst Abuse Treat Prev Policy (2013) 8(1):3. doi:10.1186/1747-597X-8-3

39. Behm-Morawitz E, Lewallen J, Choi G. A second chance at health: how a 3D virtual world can improve health self-efficacy for weight loss management among adults. Cyberpsychol Behav Soc Netw (2016) 19(2):74-9. doi:10.1089/ cyber.2015.0317

40. Reid DT. Benefits of a virtual play rehabilitation environment for children with cerebral palsy on perceptions of self-efficacy: a pilot study. Pediatr Rehabil (2002) 5(3):141-8. doi:10.1080/1363849021000039344

41. Poushter J. Smartphone Ownership and Internet Usage Continues to Climb in Emerging Economies. Pew Research Center (2016). Available from: http:// www.pewglobal.org/2016/02/22/smartphone-ownership-and-internet-usage-continues-to-climb-in-emerging-economies/

42. eMarketer.2Billion Consumers Worldwideto GetSmart(Phones) by 2016.(2014). Available from: http://www.emarketer.com/Article/2-Billion-ConsumersWorldwide-Smartphones-by-2016/1011694

43. Smith A. U.S. Smartphone Use in 2015. Pew Research Center. (2015). Available from: http://www.pewinternet.org/2015/04/01/us-smartphone-use-in-2015/

44. Griffiths F, Lindenmeyer A, Powell J, Lowe P, Thorogood M. Why are health care interventions delivered over the Internet? A systematic review of the published literature. J Med Internet Res (2006) 8(2):e10. doi:10.2196/ jmir.8.2.e10

45. Fiscella K, Franks P, Gold MR, Clancy CM. Inequality in quality: addressing socioeconomic, racial, and ethnic disparities in health care. JAMA (2000) 283(19):2579-84. doi:10.1001/jama.283.19.2579

Conflict of Interest Statement: The author declares that the research was conducted in the absence of any commercial or financial relationships that could be construed as a potential conflict of interest.

Copyright $\odot 2016$ Graham. This is an open-access article distributed under the terms of the Creative Commons Attribution License (CC BY). The use, distribution or reproduction in other forums is permitted, provided the original author(s) or licensor are credited and that the original publication in this journal is cited, in accordance with accepted academic practice. No use, distribution or reproduction is permitted which does not comply with these terms. 